\title{
Service Oriented Architecture Based SDI Model for Mineral Resources Management in India
}

\author{
Rabindra K. Barik ${ }^{1, *}$, Arun B. Samaddar ${ }^{2}$ \\ ${ }^{1}$ M. N. National Institute of Technology Allahabad, India \\ ${ }^{2}$ National Institute of Technology Sikkim, India \\ *Corresponding Author: rabindra.mnnit@gmail.com
}

Copyright (C) 2014 Horizon Research Publishing All rights reserved

\begin{abstract}
Today's economic growth rate of any country hugely depends on development of the mining sector. Thus, the level of technology employed for meeting the extraction conditions must meet environmental norms. Exploration of mineral resources in India and mining is a ready application for technologies for ensuring productivity and efficiency. Mineral resources management uses Spatial Data Infrastructure (SDI) in the study reported. SDI is a portal where each stakeholder can access, use and exchange spatial and non-spatial data for social, economic and environmental activities. The proposed system at national level may have its nodes at state level and local level on Intranet and/or Internet on Global level. The present work reports the development of an efficient interoperable Service Oriented Architecture (SOA) based SDI Model for mineral resources management in India (Acronym: MRII (Mineral Resources Information Infrastructure)) to provide better geospatial web services for different applications in terms of their functionality, ease of operation and performance as applied in various mineral resources management systems. The MRII is modular. It allows the publishing of web service descriptions as well as to submit requests to discover the web services of user's interests. The model supports integration of applications and uses thin-client architecture. Web Map Service (WMS), Web Features Service (WFS) and Web Catalogue Service (CS-W) of Open Geospatial Consortium (OGC) standards have been used for sharing and exchange of geospatial data in MRII. The open source GIS software, used for development of MRII, include Quantum GIS for creation of mineral resources geospatial database, PostGIS for storing of spatial database, MYSQL for storing of security aspects of spatial and non-spatial data; ALOV, GeoServer, GeoNetwork, GeoWebCache and Apache Tomcat for imparting geospatial web capabilities and PHP (Hypertext Preprocessor), JSP (Java Server Pages) and GeoExt (Geo Extension) for dynamic server side scripting. The developed MRII presently provides detailed information about mineral resources in India as a test case and aims to deliver spatial information at affordable cost. The same may be used in future for other countries on expanding the volume of spatial data to include the Globe.
\end{abstract}

Keywords SDI, SOA, Open Source GIS, Mineral Resources

\section{Introduction}

Mineral Resource exploration is an important economic activity which contributes significantly to the economy of India. The country exports a variety of mineral which are found in abundance its geographically diverse regions. Mining sector is facing an increased competition on account of globalisation and the level of technology employed thereby necessitating new initiatives for meeting the new challenges of better extraction conditions. Mineral resources are limited, precious and non-renewable which require proper management and standardisation. The standardisation and scientific management not only provide the efficient use and exploitation of mineral resources but also relates to social sustainable development [1].

There is a need to make coordinated efforts to encourage greater investment in exploration and mining as well to integrate modern technologies like GIS, remote sensing and GPS to increase the productivity and efficiency of this sector [2]. There is a need to establish a well organised Mineral Resources Information Infrastructure with the help of GIS technology in India.

GIS has wider applications in decision making, storage of various kinds of data, bringing data and maps to a common scale for user need, superimposing, querying and analysing the large amount of data and designing and presenting final maps and reports to administrator and planner [3]. GIS can deal with large amount of spatial data at different scales as well as non-spatial data for deriving useful information in maps/ tabular from for better understanding for organised development. The utility and application of GIS for planning of land resources and decision making has become widely popular and are being used for a wide range of applications.

With the integration of web technology with GIS, it givesrich functionality in terms of spatial data sharing on the 
web. It can provide a real time and dynamic way to represent information through maps on web [4]. So there is a need to establish a well organised Spatial Data Infrastructure (SDI) which is a portal where each stakeholder can access, use and exchange spatial data for social, economic and environmental application. Geospatial Web Service is one of the key technology require for development and implementation of SDI. Design and implementation of SDI is used service oriented architecture (SOA) which can be used for sharing mineral resources information on web which will enable the foreign investor to quickly look into the problem and prospects of investment in mineral resources exploitation in India.

Fortunately, there are many open source software that can compete the proprietary software in the field of GIS. Developers have created several open source libraries and GIS suites to cope with the flood of GIS data and their formats [8]. The goal of Open Geospatial Consortium (OGC) is to encourage the use of open source GIS standards and development of community-led projects. The available open source GIS software can be used for the works related to database creation, spatial modelling and geospatial web based services [5]. The open source GIS software used for development of SDI include Quantum GIS for creation of geospatial database, MYSQL for storing of security aspects and non-spatial data, ALOV, GeoServer and Apache Tomcat for imparting geospatial web capabilities and PHP: Hypertext Preprocessor, JSP: Java Server Pages and GeoExt: Geo Extension for dynamic server side scripting.

\section{Mineral Resources Management: Indian Scenario}

India is endowed with significant mineral resources. India produces 89 minerals out of which 4 are fuel minerals, 11 metallic, 52 non-metallic and 22 minor minerals [6]. The entire metallic production is accounted for by iron-ore, copper-ore, chromite and/or zinc concentrates, gold, manganese ore, bauxite, lead concentrates, and silver. Amongst the non-metallic minerals, 92 percent of the aggregate value is shared by limestone, magnesite, dolomite, barytes, kaolin, gypsum, apatite \& phosphorite, steatite and fluorite.

India is the world's largest producer of mica blocks and mica splittings. With the recent spurt in world demand for chromite, India has stepped up its production to reach the third rank among the chromite producers of the world. Besides, India ranks 3rd in production of coal \& lignite and barytes, 4th in iron ore, 6th in bauxite and manganese ore, 10 in aluminium and 11th in crude steel in the World. The Ministry of Mines is responsible for the survey and exploration of all minerals, other than natural gas, petroleum, and atomic minerals; for mining and metallurgy of non-ferrous metals like aluminum, copper, zinc, lead, gold, nickel, etc., and for the administration of the Mines and
Minerals (Regulation and Development) Act, 1957.

The public sector contributes over 88 percent of the total value of mineral production. Public sector enterprises like the National Mineral Development Corporation, Kudremukh Iron Ore company, Steel Authority of India Limited and Orissa Mining Corporation dominate the iron ore sector. Two Public sector enterprises - National Aluminum Company and Bharat Aluminum Company, account for over 66 percent of alumunium production in India. Hindustan copper Limited predominates the copper ore mining sector, zinc-lead ore mining and processing is dominated by Hindustan Zinc Limited. Bharat Gold Mines, a public enterprises of the Government of India and Hutti Gold Mines Limited (a Government of Karnataka undertaking), are engaged in the mining of gold. Rajasthan State Mines and Minerals Limited and Andhra Pradesh Mining Development Corporation predominate the mining of rock phosphate and barytes respectively [7].

However, the information so far are available as bulletins from different agencies, or at some specific websites. None of them are comprehensive and easily available. Moreover, for exploitation of mineral resources it is important to have a better understanding and perception of the geographical location, user base, port and transport facilities, electricity, skill manpower, availability of experts and various agencies etc. This may be well achieved through a spatial information system with geographic references. Further, in the era of globalization, it is important to make this information available on the Web for ready access to the world community for FDI etc. This will also give a great scope for the expertise, especially the site specific expertise available in the country to put forward their skills which would be required by the investors any way. This also will be a powerful tool for the policy makers and government for mineral resources management while implemented in the specific manner.

Thus, the role of a GIS based information system in mineral resources from the perspective of the user is an urgent need. In the present era of information age, new tools and technologies have emerged to collect, store, retrieve and analyze various types of information related to mineral deposits. Today, Two GIS packages, M.R.I.S and MINFO are used for mineral resources information management which are derived from the concept of MERIGOLD, a database on gold deposits of Australia. But both have not the capability of web enabled although it has greater efficiency in analysis [8-9]. WeBSAS is another WebGIS system which provides the web capability for sharing of data through web [10]. But the WeBSAS is very difficult to implement and it does not support OGC specification. These challenges cause barriers in extensively sharing mineral resources data and restrain the effectiveness in understanding and responding to proper management. To overcome these challenges in mining sector, mapping and sharing of mineral resources information in an interoperable framework based on OGC specifications under GIS environment is the need of the hour 


\section{SOA Based SDI}

SDI provides an environment within which organisations interact with technologies to foster activities for using, managing and producing geographic data. It is the technology, policies, standards, human resources, and related activities necessary to acquire, process, distribute, use, maintain and preserve spatial data [11-13]. The core components of SDI can be viewed as policy, networking, standards, people and data. These can be grouped into different categories based on the nature of their interactions within the SDI Model [14-15].

The Service Oriented Architecture tries to construct a distributed, dynamic, flexible, and re-configurable service system over Internet that can meet information and service requirements for development of SDI. The key component in the SOA based SDI is geospatial web service i.e. a well defined set of actions. It is self contained, stateless, and does not depend on the state of other services [16-17].

A geospatial web service is an application that can retrieve data from GIS databases and provide geographic information through a browser interface to end-users [18]. Thus, geospatial web capabilities indicate to a web based GIS which can be modelled using the client-server architecture. In development of SDI Model, the major focus has been on SOA based geospatial web service by using spatial data. According to services, it can be grouped data service, processing service and catalog service [19]. Data service is tightly coupled with specific data sets and offers WFS, WMS and WCS[20-21].

The basic operations in SOA based SDI Model include publish, find and bind. To be able to integrate any services into SOA based architecture, it should provide at least one of the SOA's major operations. Figure 1 shows three major functionalities in SOA based SDI.

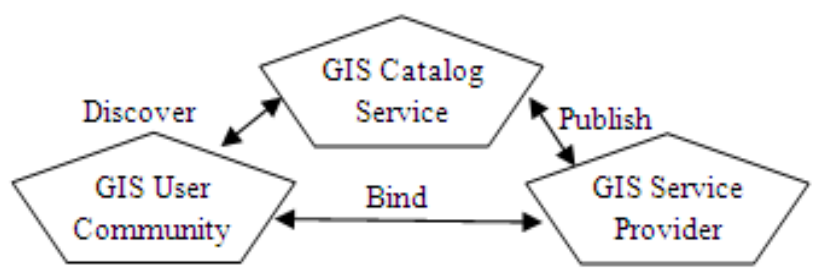

Figure 1. Three major functionalities in SOA [19]

In SOA based SDI Model, there are three types of key actors i.e. service requester or GIS user community, GIS service provider and GIS catalog service. Catalog service can be called registry service or broker but their main functionality is almost same in most of the applications. Catalog service helps the requestors to discover or find the right services. When a service provider sets up a service over the internet and wants the users to use their service, it needs to publish their services. When a requestor requests a service, the requestors and service brokers need to collaborate to find the right services. After the right service is found, requestor and provider bind or negotiate as to format of the request. Then, the requestor can access and invoke services of the provider [22-23].

\section{Objective of the Present Work}

The main aim of the present work is to development and implementation of SOA based SDI Model for mineral resources management in India. Open source GIS and OGC standards have been used for the development of Mineral Resources Information Infrastructure (Acronym: MRII). The prototype MRII developed is interoperable and uses thin-client architecture. The open source GIS software used for development of MRII includes Quantum GIS for creation of geospatial Mineral Resources database, PostGIS and MYSQL for storing of spatial and non-spatial data, ALOV, GeoServer, GeoNetwork, GeoWebCache, WAMP and Apache Tomcat for imparting geospatial web capabilities in terms of WMS, WFS, WCS and CS-W. PHP: Hypertext Preprocessor, JSP: Java Server pages and GeoExt: Geo Extension are used for dynamic server side scripting for development of SDI Model.

\section{Methodology Adopted}

For development of SDI Model, the main focus has been on the use of a practical approach to explore and extend the concept of SDI in education sector. The developed SDI Model should provide an effective and efficient means of sharing geospatial data and non-spatial data on the web using GIS in a secure way. The proposed SOA based SDI Model in which it follows the basic over view of service provider, service consumer and catalog service.

In MRII, it focuses on OGC compliant web services on vector and raster data. Admin is managing the data and gives authority to the different user and Catalog is updated by catalog admin. In catalog, various services are published and ready for service requester i.e. web client and web client discovers the required service. Finally, The required services consumed by the service consumer. This architecture can be fulfilling the most sophisticated workflow for development of SDI Model.

In the initial phase, it is important to model geospatial database. For achieving MRII, different topographical maps of India have been taken and geospatial database has been created in terms of several mineral resources available and find out the detailed information regarding all mineral resources. The next phase is to store all the geospatial databases is in shape file format and to link each spatial component with its specific attributes. The Business Process Data (BPD) is meant to give additional storage for security purpose and for business application. In the next phase, ALOV and WAMP Server have been integrated for imparting the geospatial web capabilities with respect to Web Map Services (WMS), Web Feature Services (WFS) and Web Coverage Services (WCS). Geospatial web capabilities have been implemented on the web using the 
thin client architecture. MySQL is used for storing of security aspects and non-spatial data for decision making. PHP: Hypertext Preprocessor language has been used for dynamic server side scripting. Figure 2 shows the layered architectural view that comprises of open source resources.

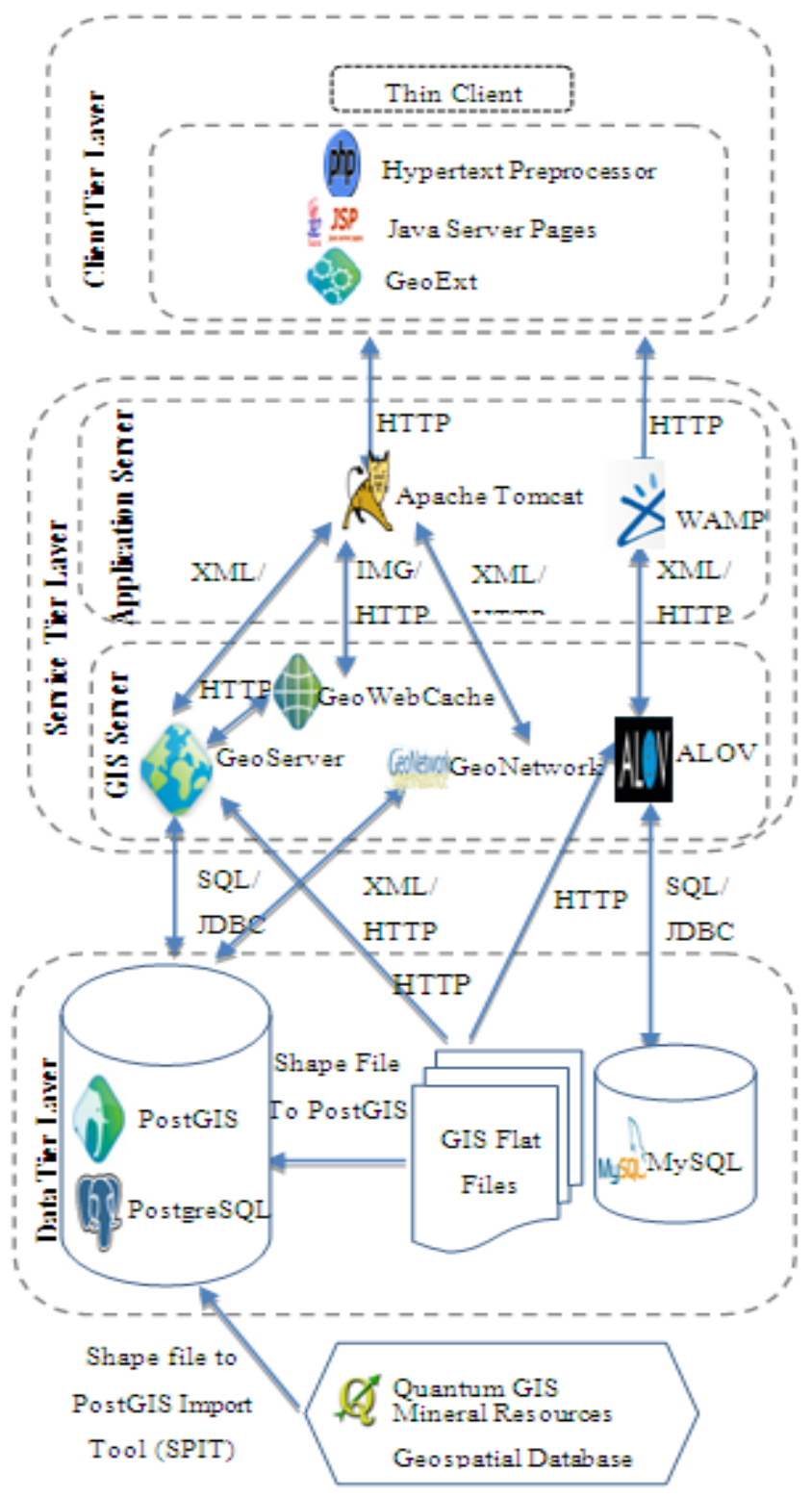

Figure 2. Layered Architectural view of open source resources

In the initial phase, it is important to model geospatial database. For achieving MRII, different topographical maps of India have been taken and geospatial database has been created in terms of several mineral resources available and find out the detailed information regarding all mineral resources. The next phase is to store all the geospatial databases is in shape file format and to link each spatial component with its specific attributes. The Business Process Data (BPD) is meant to give additional storage for security purpose and for business application. In the next phase, ALOV and WAMP Server have been integrated for imparting the geospatial web capabilities with respect to
Web Map Services (WMS), Web Feature Services (WFS) and Web Coverage Services (WCS). Geospatial web capabilities have been implemented on the web using the thin client architecture. PostGIS and MYSQL are used for storing of spatial and non-spatial data for decision making. PHP: Hypertext Pre-processor, JSP: Java Server Pages and GeoExt: GeoExtension languages have been used for dynamic server side scripting in the framework.

\section{Prototype Development}

The prototype development of MRII is based on Jacobson's method of Object Oriented Software Engineering (OOSE) method which involves the formation of models that capture the actors of the system and their behaviour for each of the design stages [24-25]. The models are made up of objects representing real world entities. This is a natural way for people to describe their environment; and helps in reducing the semantic gap between the developed model and the real world. Figure 3 shows the complete process model for development of MRII framework.

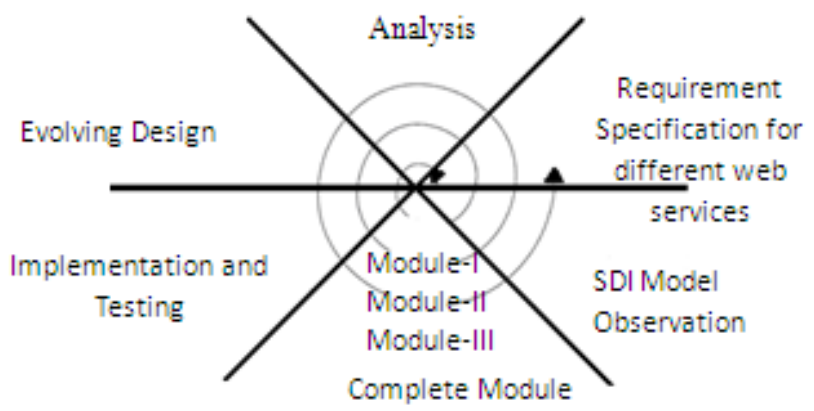

Figure 3. Process Model for MRII

In OOSE approach, the software development process adopts a sequence of steps including requirements specification, analysis and design, implementation and testing, complete module and model observation. The process is usually cyclic or incremental in nature and each implementation refines the analysis and design stages through evaluation and testing of a completed module. Further, the incremental development strategy allowed the problem of constructing this framework to be tackled in smaller, more manageable portions of increasing complexity. In addition, it is expected that each module would reveal unique features related to the requirements of the underlying infrastructure and enable exploration of the interfaces between SDI components.

The requirements stage of application design aims to specify the behaviour of the framework from the perspective of a user. Understanding potential system users in terms of knowing who they are and what they want to do facilitate system development. The use case model is one of the important aspects in this phase which basically specifies a sequence of actions that need to be performed. The construction of use case model involves how a user would 
interact with the system to identify the various system objects and highlights the need for careful consideration to be given to the issues of human computer interaction within the network environment.

The sequence diagram in Figure 4 presents a best case scenario. This success story should be duly associated with a number of alternative scenarios to be invoked at each step. The alternative scenarios are not presented and require the involvement of real life environment.

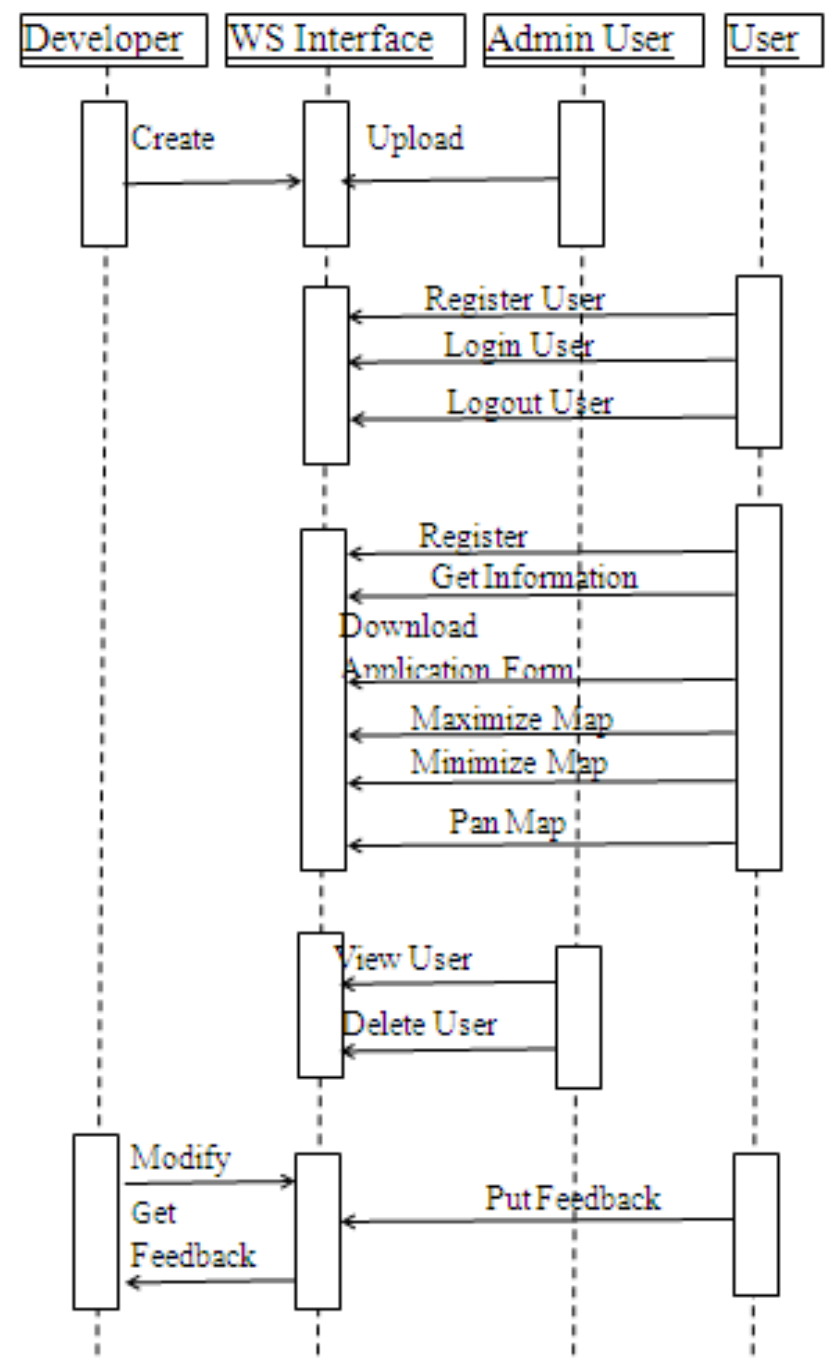

Figure 4. Sequence Diagram for MRII (Best case scenario) Similarly, Figure 5 presents only a rough cut of the first iteration of collaborative diagram.

The framework consists of three main modules, e.g., module I for registration, module II for Mineral Resources Information Mapping, and module III for Utility Services. Module I describes the detailed process to register the user for authentication. After registration process, user can use the framework with full phase operation. Module II gives detailed viewing of Mineral Resources information mapping in terms of various factors associated with availability in India. Module III describes utility services, i.e., management of user level for security aspects, and uploading/ downloading features for full phase operation.

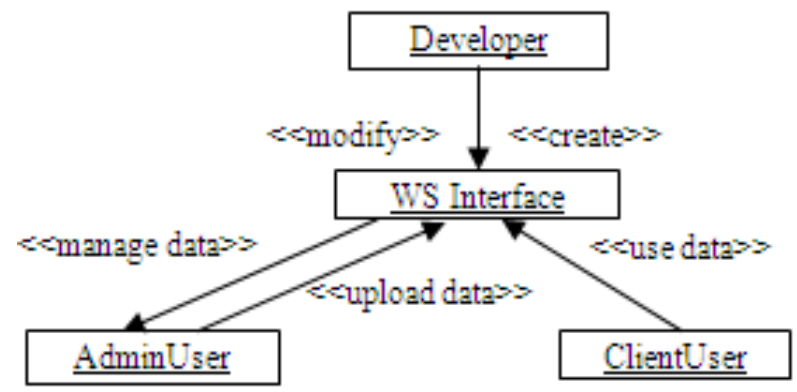

Figure 5. Collaborative Diagram for MRII (Rough cut)

The MRII framework thus developed has been shown using three illustrations. Figure 6 shows all the mineral resources information locations in India.

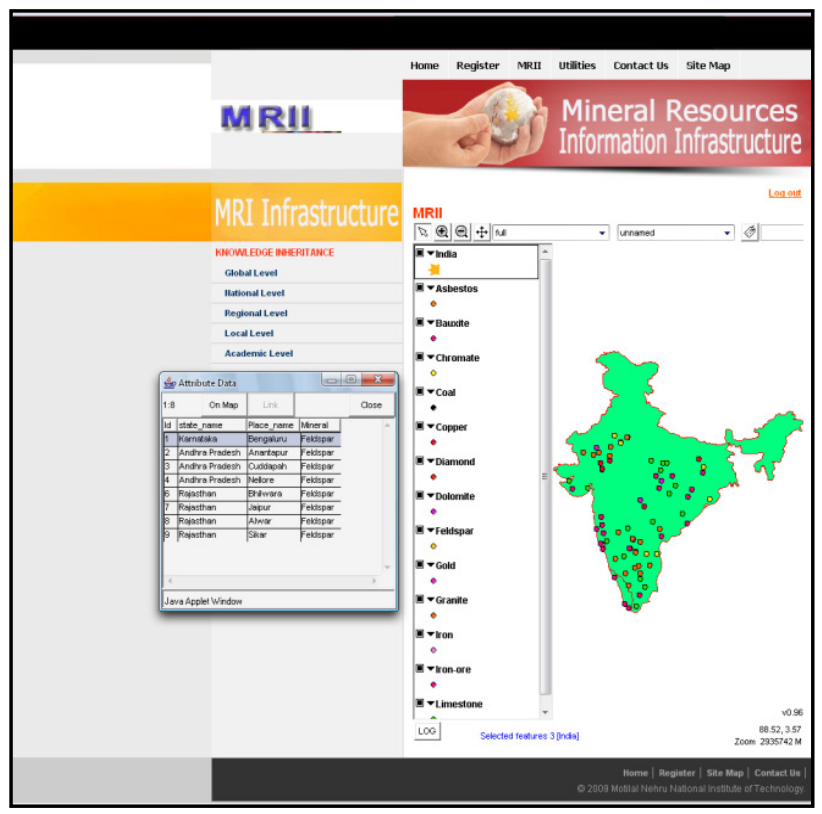

Figure 6. Map showing locations of mineral resources

\section{Concluding Remarks}

A prototype SOA based Mineral Resources Information Infrastructure (MRII) has been developed in the present work using open source GIS and research work is focused at adopting OGC standards for creating, accessing, integrating and sharing the mineral resources information on the web. The developed framework adopts a modular and flexible structure, and provides an efficient mechanism for the generation and delivery of value-added spatial information to extend the concept of geospatial web services in the field of mining sector for fulfilment of the basic requirement of SDI at national level. The experience in using open source GIS software suggests that various tools and software like Quantum GIS, ALOV, GeoServer, GeoNetwork, GeoWebCache, Apache Tomcat, WAMP, MYSQL, PostGIS $\&$, GeoExt and PHP are available for creation of spatial 
datasets and implementation of geospatial web services in comparison to costly proprietary solutions.

The developed SOA based SDI Model for management of mineral resources will also provide the basic components for delivery of mineral resources information efficiently at affordable costs and is expected to be beneficial to different mining institutes, mining industries and user community on global platform.

The main focus of the present work is to develop and implement SOA based SDI Model for Mineral Resources management in India. Therefore, the database used for the proposed system is at macro level and may be made more comprehensive in future studies. The prototype developed is operational at intranet level at the moment. The same will be put up on the Internet shortly.

\section{REFERENCES}

[1] Samaddar, Arun B., Barik, R.K. and Gupta, R.D. Web GIS for Mineral Resources Management in India, 3rd Asian Mining Congress, Hotel Taj Bengal, Kolkata, India, Jan. 22-25, Vol. 2, ISBN: 978-81-8211-069-4, PP 349-358, 2010.

[2] Paul, P.K. and Das, S. 2006. Development of a GIS-based environmental MIS for coal mining areas of West Bengal, The Journal of Institute of Engineers, India, Volume 87, PP $30-34,2006$.

[3] Broueckner, Michael and Tetiwat, Orasa. Use of Geographical Information Systems for Thailand. E-leader, Bangkok, 2008.

[4] Alesheikh , AA., Helali, H. and Behroz, HA. WebGIS Technologies and Application, Symposium on Geospatial Theory, Processing and Applications, Ottawa, ISPRS, Vol. XXXIV, Part 4, 2002.

[5] Barik, R.K., Samaddar, Arun B. and Gupta, R.D. Investigations into the Efficacy of Open Source GIS Software, International conference, Map World Forum, on Geospatial Technology for Sustainable Planet Earth, Hyderabad, India, Feb 10-13, 2009.

[6] Internet-1, http://mines.nic.in/imsector.html (Accessed: 12 September, 2012).

[7] Internet-2, http://mines.nic.in/default.html (Accessed: 12 September, 2012).

[8] Ayachi, A.K. Advance Mineral Resources Information System (M.R.I.S v 2.0) Using remote sensing and GIS Inputs. 8th Annual International Conference on Geomatic, Map India- 05, Delhi, India, 2005.

[9] Roy, Indranil , Sarkar, B. C. and Chattopadhyay, A. MINFO - a prototype mineral information database for iron ore resources of India, Computers \& Geosciences, Volume 27 , Issue 3, pp: 357 - 361, ISSN:0098-3004, 2001

[10] Vatsavai, R.R.,Burk, T.E., Wilson, B.T., Shekhar, S. A Web-based browsing and spatial analysis system for regional natural resource analysis and mapping. 8th ACM Symposium on GIS, ISBN 1-58113-319, 2001
[11] Rajabifard, A., Feeney, M. E. F. and Williamson. Future Directions for SDI Development, International Journal of Applied Earth Observation and Geoinformation, ITC, The Netherlands, Vol. 4, No. 1, pp. 11-22, 2002.

[12] Puri, Satish K., Sahay, Sundeep and Georgiadou, Yola. A Metaphor-Based Sociotechnical Perspective on Spatial Data Infrastructure Implementations: Some Lessons from India, Research and Theory in Advancing Spatial Data Infrastructure Concepts, ESRI Press, pp.161-173, 2007.

[13] Rawat, Sujata. Interoperable Geo-Spatial Data Model in the Context of the Indian NSDI, Thesis (Master), ITC, The Netherlands, 2003.

[14] Mansourian, A., Rajabifard, A., Valadan Zoej, M.J. and Williamson. Using SDI and web-based system to facilitate disaster management, International Journal of Computers \& Geosciences, Vol. 32, pp. 303-315, 2005.

[15] GSDI Cookbook. Developing spatial data infrastructure: The SDI Cookbook (online), 2004. [Available from: http://www.gsdi.org/docs2004/Cookbook/ cookbookV2.0.pdf] (Accessed: 15 November, 2009).

[16] Davies, Jessica. Expanding the spatial data infrastructure model to support spatial wireless applications, Thesis $(\mathrm{PhD})$. Department of Geomatics, The University of Melbourne, 2003.

[17] Morris, Steven. Geospatial Web Services and Geo archiving: New Opportunities and Challenges in Geographic Information Services, LIBRARY TRENDS, Vol. 55, No. 2, pp. 285-303, 2006.

[18] Vaccari, Lorenzino, Shvaiko, Pavel and Marchese, Maurizio. A geo-service semantic integration in Spatial Data Infrastructure, International Journal of Spatial Data Infrastructures Research, Vol.4, pp. 24-51, 2009.

[19] Xiaolin, Lu. An Investigation on Service Oriented Architecture for constructing Distributed WebGIS Application, IEEE International Conference on Services Computing (SCC'05), vol. 1, pp.191-197, 2005.

[20] OGC. Open GIS Web Map Server Cookbook (online), 2004. [Available from: http://www.opengeospatial.org/standards/w $\mathrm{ms}]$

[21] Harper, Eric. Open Source Technologies in Web-based GIS and Mapping, Master's Thesis, Northwest Missouri State University, Maryville Missouri, 2006.

[22] Barik, Rabindra K., Samaddar, Arun B., Samaddar, Shefalika G.. Service Oriented Architecture based SDI Model for Geographical Indication Web Services, International Journal of Computer Applications, Vol. 25, No. 4, pp. 42-49, 2011.

[23] Becker, Christoph, Kulovits, Hannes., Rauber, Andreas ., Hofman, Hans., Plato. A Service Oriented Decision Support System for Preservation Planning, JCDL, Pitsburgh, Pennsylvania, USA, June 15-20, 2008.

[24] Mall, Rajiv. Fundamentals of Software Engineering, Rev. 2nd Edition, Prentice-Hall of India Pvt. Ltd, India, 2004.

[25] Davies, Jessica. Expanding the spatial data infrastructure model to support spatial wireless applications, Thesis $(\mathrm{PhD})$. Department of Geomatics, The University of Melbourne, 2003. 